of theatre time; disturbs the routine of busy laboratories as well as putting the pathologist under pressure; is far from uniformly available; and may on occasion make a definitive operation technically less easy.

So it is no surprise to find reports beginning to appear on methods to make the preoperative diagnosis more firm or to establish it beyond doubt. Many surgeons have used needle aspiration of breast lumps ${ }^{23}$ to clinch the diagnosis of cyst (and surgeons in breast clinics are all familiar with the smile of relief from the patient when, convinced she has a rapidly advancing tumour, she is shown the contents of a syringe) and to increase diagnostic confidence in solid lesions. Suitably handled, needle aspiration fragments from solid tumours can yield a useful cytological diagnosis in a high proportion of cases. The best technique ${ }^{4}$ has proved to be suspension in fixative, followed by filtration through and direct staining of an ultrafine filter disc, which gives cytological reportability of well over $90 \%$ and accuracies of over $95 \%$. In contrast, smear methods continue to return about $60^{\circ}$ o accuracy. ${ }^{5}$

Though cytology may strengthen the clinician's opinion, and thus enable him to talk with heightened confidence to the patient about the likely path along which treatment will proceed, the observation of malignant-like cells without an appreciation of tissue architecture is not sufficient to indicate ablative surgery. Only histological evidence permits mastectomy. Drill biopsy has been used successfully, but the technique is a little complicated and cumbersome. ${ }^{6}$ Several authors have reported experience with needle biopsy using the Travenol Trucut device, which cuts a core similar or superior to a Vim-Silverman needle. The group in Cardiff who pioneered the technique ${ }^{7}$ used it primarily on patients with a firm clinical diagnosis of breast cancer, their major objective being to save time and resources. A positive result was achieved in nearly two-thirds of their patients, and a week's operating time per year was thus saved. More recently, workers in Sydney, Australia, ${ }^{8}$ and in Nottingham ${ }^{5}$ have extended Trucut biopsy to make it more versatile. Both groups use a sequential approach, ${ }^{9}$ classifying their patients stepwise according to the clinical findings - a single lump; the presence of liquid at fine needle aspiration; and clinical "suspicion" of cancer. Trucut biopsy on the last provides a reliable diagnostic indication in three-quarters of patients, though if any clinical doubt remains this must clearly override a negative biopsy report.

Needle biopsy will be increasingly used in the diagnosis of breast disease. The sequential protocols used will vary from team to team, but they should centre on reducing error to a minimum, with the supplementary benefits of informing the patient and conserving resources. The Nottingham workers, who had their cytologist read the preparations blind, do not see a continuing place for cytological examination and prefer to use Trucut biopsy on all lesions found to be solid. Others differ ${ }^{4}$ : it is fair and realistic to supply clinical information, which is obviously more critical to cytologist than histopathologist. Both techniques will probably be used to the benefit of patients and the planning of surgical care.

${ }^{1}$ Dudley, H, Medical Hypotheses, 1976, 2, 164

2 Franzén, S, and Zajicek, J, Acta Radiologica, Therapy, Physics and Biology, 1968, 7, 241.

3 Webb, A J, British fournal of Surgery, 1970, 57, 259.

4 Coleman, D, et al, Clinical Oncology, 1975, 1, 27.

${ }^{5}$ Davies, C J,et al, British fournal of Surgery, 1977, 64, 326.

6 George, W D, and Burn, J I, Clinical Oncology, 1975, 1, 291.

7 Roberts, J G, et al, Clinical Oncology, 1975, 1, 297

${ }^{8}$ Magarey, C, and Watson, N, Australian and New Zealand fournal of Surgery, 1976, 46, 344

9 Jamieson, C, and Dudley, H, Lancet, 1973, 2, 314.

\section{Otitis media-then what?}

At a time when able thinkers are attempting to define the principles which should govern allocation of limited resources between the different health service disciplines and between different activities within these disciplines ${ }^{12}$ a thought may be spared for the doctor who has to decide when to use those specialist services which are available to him. It is all very well for him to read widely, but attempting to interpret (and sometimes even to understand) reports of new developments may be quite another matter, especially when they seem to promise an important advance in the handling of an everyday problem.

Recently two papers from across the Atlantic reported on different aspects of middle ear disease in children. The more specialised paper $^{3}$ discussed the technique of tympanometry (measurement of the flow of sound energy in the ear at different air pressures) and its possible use in diagnosing middle ear effusion-an important cause of both physical and educational handicap in young children. The test proved reliable in detecting the presence of middle ear effusions, and the Boston authors suggested that it might be of practical diagnostic value from the age of 4 months. For ethical reasons they did not attempt to confirm the absence of effusion in patients with normal tympanograms, making evaluation of tympanometry in the routine follow-up of otitis media that bit harder. But how many children might require this service and which ones should be referred for it?

The second paper $^{4}$ reported that in a private American practice 81 of 246 babies $(33 \%)$ had an episode of otitis media in their first year of life. If that figure seems high a further American study, specifically aimed at assessing incidence, found one child affected out of every two studied. ${ }^{5}$ Comparable figures from contemporary British practice are hard to find. The eardrums are not examined in all consultations for upper respiratory illness, ${ }^{6}$ and diagnostic habits in this field vary so much between doctors that little reliance can be placed on retrospective studies of general practice morbidity. ${ }^{7}$ Studies from Liverpool and Edinburgh ${ }^{8} 9$ suggested that 22 of 119 children $(18 \%)$ and 20 of $122(16 \%)$ respectively presented with otitis media in the first year of life and that in each of the first seven years of life more than $10 \%$ of children consult in any one year with otitis media.

What is the incidence of residual deafness? The Liverpool study $^{8}$ reported an audiometrically discernible hearing loss of 30 decibels or more in $25 \%$ of children six months after the acute attack; $38 \%$ of their patients with otitis media were referred to a specialist. The Edinburgh workers arranged specialist follow-up for all of their children (83\% attended) and reported that three months after the attack there was a 15 decibel loss in $45 \%$ of patients over the age of 4 . A later paper $^{10}$ found that only $6 \%$ of 121 children tested out of 171 originally suffering acute otitis media suffered permanent damage to hearing in one or both ears but that many more had a transitory loss. The average time between the attack and complete recovery of hearing was 23 months. In contrast, the 1957 report of the MRC survey of otitis media, ${ }^{11}$ though recording figures of incidence comparable with these later studies, noted only 32 children out of 968 (3\%) with "deafness" at six months after the acute attack.

How can these studies be added together to make a sensible whole? It is unfair to blame individual research workers simply because their results do not dovetail with other published work. But interpretation of research reports would be 
easier if greater attention was paid to the basic epidemiological rules of precise description of what is being studied or observed and careful definition of the populations covered by the observations. The difficulties could be reduced still further if specialists, generalists, and epidemiologists more often discussed the design of research before it took place rather than lamenting missed opportunities afterwards. And how much easier it would be for the clinician looking for guidance.

${ }^{1}$ Bennett, A E, and Holland, W W', Lancet, 1977, 1, 464

2 Barr, A, and Logan, R F L, Lancet, 1977, 1, 994.

${ }^{3}$ Shurin, P A, Pelton, S I, and Finkelstein, J, New England fournal of Medicine, 1977, 296, 412.

4 Hoekelman, R A, Pediatrics, 1977, 59, 119

5 Howie, V M, Ploussard, J H, and Sloyer, J, American fournal of Diseases of Children, 1975, 129, 676.

${ }^{6}$ Buchan, I C, and Richardson, I M, Time Study of Consultations in General Practice, Scottish Health Service Studies No 27. Edinburgh, Scottish Home and Health Department, 1973.

${ }^{7}$ Howie, J G R, Fournal of the Royal College of General Practitioners, 1973, 23, 895.

${ }^{8}$ Lowe, J F, Bamforth, J S, and Pracy, R, Lancet, 1963, 2, 1129.

- Paterson, J E, and Maclean, D W, Scottish Medical fournal, 1970, 15, 289.

10 Neil, J F, et al, British Medical fournal, 1966, 1, 75.

11 Medical Research Council, Lancet, 1957, 2, 510.

\section{Headaches and coffee}

An average cup of coffee contains nearly $200 \mathrm{mg}$ of caffeine, ${ }^{1}$ but tea, cocoa, and cola drinks also contain substantial amounts. The usual therapeutic dose of caffeine is $100-300 \mathrm{mg}$, so that many of us drink several times this amount each day. Indeed, the annual consumption of coffee in Britain increased from $2.5 \mathrm{lb}(1.1 \mathrm{~kg})$ per head in 1965 to $3.6 \mathrm{lb}(1.5 \mathrm{~kg})$ in 1969 . Both tea and coffee contain other substances, including oils and tannin, which may contribute to their effects.

The clinical effects of caffeine and related xanthines have been extensively studied, and, though some are still disputed, workers agree that xanthines stimulate the central nervous system, increase respiration, affect smooth muscle, and cause a diuresis. These effects are mediated by inhibition of the enzyme phosphodiesterase, leading to a raised concentration of cyclic AMP2.

Too much coffee produces symptoms indistinguishable from those of anxiety neuroses: recurrent headaches, mental irritability, cardiac arrhythmias, and gastrointestinal disturbances. ${ }^{3}$ Nevertheless, we do not know the prevalence of caffeinism and of coffee allergy, ${ }^{4}$ or what contribution an average coffee consumption makes to our normal balance of behaviour and health. Both regular and decaffeinated coffee stimulate gastric acid secretion: this effect is greater than that of caffeine alone, but the constituent responsible has not been isolated, and patients with active peptic ulcers should avoid drinking too much coffee even if it has been decaffeinated. Coffee also raises the pressure at the lower oesophageal sphincter, whereas caffeine itself is without effect. ${ }^{5}$

Coffee consumption has been said to be implicated in causing renal cancer, ${ }^{6-8}$ but these findings have not been confirmed in other studies. ${ }^{9-11}$ Nevertheless, coffee does contain phenolic materials which are readily oxidised and can catalyse the formation of $\mathrm{N}$-nitrosamine within the digestive tract, and this could be a causal link. ${ }^{12}$ Coffee consumption has also been correlated with the incidence of myocardial infarction, ${ }^{13}$ while in another study 276 patients admitted with acute myocardial infarction were found to drink more coffee than matched controls. ${ }^{14}$ This effect may have arisen ${ }^{15}$ from a coffee-induced increase in serum lipids. Alternatively, coffee might act by releasing catecholamines. More recently, however, no association was found between coffee consumption and myocardial infarction in several careful prospective studies, ${ }^{16-18}$ and we have insufficient evidence to include coffee in those factors linked with coronary deaths.

Even so, doubts about the long-term safety of caffeinecontaining beverages may combine with their soaring cost to encourage a search for alternatives. Abrupt withdrawal of coffee may have its own problems: sudden discontinuation of coffee drinking may be associated with headaches, which respond to caffeine. ${ }^{1920}$ The cause of these is unknown, but, as coffee causes cerebral vasoconstriction (in contrast with its dilator action on peripheral blood vessels) withdrawal may be succeeded by dilatation of the cerebral blood vessels. Clearly, there is much more to coffee than caffeine.

${ }^{1}$ Medvei, V C, fournal of International Medical Research, 1974, 2, 359.

2 Butcher, R W, and Sutherland, E W, fournal of Biological Chemistry, 1962, 237, 1244

${ }^{3}$ Greden, J F, American Fournal of Psychiatry, 1974, 131, 1089.

- Ulett, G A, and Perry, S G, Annals of Allergy, 1975, 34, 150.

5 Cohen, S, and Booth, G H, New England fournal of Medicine, 1975, 293, 897.

'Shennan, D H, British fournal of Cancer, 1973, 28, 473.

7 Schmauz, R, and Cole, P, Journal of the National Cancer Institute, 1974, 52, 1431.

${ }^{8}$ Fraumeni, J F, Scotto, J, and Dunham, L J, Lancet, 1971, 2, 1204

9 Wynder, E L, Mabuchi, K, and Whitmore, W F, fournal of the National Cancer Institute, 1974, 53, 1619.

${ }^{10}$ Morgan, R W, and Jain, M G, Canadian Medical Association fournal, 1974, $111,1067$.

11 Armstrong, B, Garrod, A, and Doll, R, British fournal of Cancer, 1976, 33, 127

12 Challis, B C, and Bartlett, C D, Nature, 1975, 254, 532.

${ }_{13} \mathrm{Jick}, \mathrm{H}$, et al, New England fournal of Medicine, 1973, 289, 63.

${ }^{14}$ Boston Collaborative Drug Surveillance Program, Lancet, 1972, 2, 1278.

${ }^{15}$ Little, J, et al, Lancet, 1966, 1, 732.

${ }^{16}$ Dawber, T R, Kannel, W B, and Gordon, T, New England fournal of Medicine, 1974, 291, 871 .

17 Hennekens, C H, et al, New England fournal of Medicine, 1976, 294, 633.

${ }^{18}$ Klatsky, A L, Friedman, G D, and Siegelaub, A B, fournal of the American Medical Association, 1973, 226, 540.

19 Harrie, J R, Fournal of the American Medical Association, 1970, 213, 628. Shorofsky, M A, and Lamm, N, New York State fournal of Medicine, 1977, 77, 217.

\section{Little and late}

More than two years after publication of the Merrison Report $^{12}$ on the future of the GMC the Government has given a guarded acceptance to its recommendations. Mr Ennals's statement last week $^{3}$ was disappointing, however, in postponing indefinitely any measures for the serious reform of medical education, graduate clinical training, and specialist registration. No doubt he was right when he suggested that the profession was divided on these issues: but there is a limit to the length of time that consultation can be prolonged usefully.

Meanwhile there need be no qualifications on our welcome for the undertaking from the Government to introduce a simple Bill next session to reform the constitution of the GMC so that elected members form the majority. The whole weary saga of the retention fee and the groundswell of discontent among apolitical doctors showed how deep was the resentment of the old autocratic structure. A democratically elected GMC should command the respect of doctors-which it will need if it is to act firmly in maintaining standards of professional competence as well as standards of behaviour.

${ }^{1}$ Report of the Committee of Inquiry into the Regulation of the Medical Profession, Chairman Dr A W Merrison, FRS. London, HMSO, 1975, Cmnd 6018, price $£ 1 \cdot 75$.

${ }^{2}$ British Medical fournal, 1975, 2, 155.

${ }^{3}$ Hansard, House of Commons, 18 July 1977, col 347. 